\title{
Degradação de poliestireno expandido por larvas de Tenebrio molitor Linnaeus, 1758 (Coleoptera: Tenebrionidae)
}

\author{
Eduardo Pigozzi da Costa*, Mariana Garcia Martinez da Silva
}

Universidade Paulista - UNIP. Rua Apeninos, 267. Aclimação. São Paulo-SP, Brasil (CEP 01533-000).*E-mail: eduardopigozzi12@gmail.com.

Resumo. 0 poliestireno expandido (EPS), conhecido popularmente no Brasil como isopor, apresenta propriedades muito interessantes para a economia, mas o seu descarte incorreto é causador de muitos problemas, principalmente no que se refere ao meio ambiente. No entanto, um grupo de pesquisadores da Universidade Stanford, Califórnia (EUA), descobriu que bactérias do gênero Exiguobacterium, encontradas no trato digestório do Tenebrio molitor Linnaeus, 1758 (Coleoptera: Tenebrionidae), conseguem metabolizar naturalmente o EPS. Estes insetos são conhecidos popularmente como tenébrio e possuem ampla distribuição geográfica e grande capacidade de adaptação a diversos ambientes, inclusive àqueles alterados por atividades antrópicas. Esta pesquisa teve como objetivo analisar o comportamento fisiológico de larvas de T. molitor através da oferta de EPS como dieta principal, a fim de utilizar estes animais como possíveis biocontroladores da degradação do EPS. Para isto, foi realizado um bioensaio em laboratório que consistiu em comparar três grupos distintos de larvas, subdivididos em três colônias cada um. Cada grupo recebeu condições de ambientação e alimentação próprios, no intuito de comparar o desenvolvimento de cada larva até o seu estágio adulto. Constatou-se, então, que os percentuais de alimento consumido eram semelhantes independentemente de quais materiais eram utilizados para esse fim, além de não alterarem o desenvolvimento natural dos indivíduos.

Palavras-chave: EPS; Tenebrio molitor; Biocontroladores; Biodegradação.

\begin{abstract}
Degradation of expanded polystyrene by larvae of Tenebrio molitor Linnaeus, 1758 (Coleoptera: Tenebrionidae). Expanded polystyrene (EPS), popularly known in Brazil as isopor, shows very interesting properties for the economy, but its incorrect disposal is causing many problems, especially with regard to the environment. However, a group of researchers from Stanford University, California, found that bacteria of the genus Exiguobacterium, found in the digestive tract of the Tenebrio molitor Linnaeus, 1758 (Coleoptera: Tenebrionidae), can naturally metabolize the EPS. These insects
\end{abstract}

\author{
Recebido: \\ $22 / 12 / 2017$ \\ Aceito: \\ $22 / 03 / 2018$ \\ Publicado: \\ $30 / 04 / 2018$
}

Acesso aberto

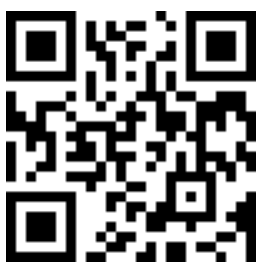

ORCID

(1) 0000-0003-1777-2819 Eduardo Pigozzi da Costa

(1) 0000-0003-4349-5966

Mariana Garcia

Martinez da Silva 
are popularly known as mealworm beetles and have a wide geographic distribution and great adaptability to various environments, including those altered by anthropic activities. The objective of this research was to analyze the physiological behavior of T. molitor larvae through the supply of EPS as the main diet, in order to use these animals as possible biocontrollers of EPS degradation. For this, a laboratory bioassay was performed that consisted of comparing three distinct groups of larvae subdivided into three colonies each. Each group received proper conditions of living and food in order to compare the development of each larva to its adult stage. It was found that the percentages of food consumed were similar regardless of what materials were used for that purpose, and did not alter the individuals' natural development.

Keywords: EPS; Tenebrio molitor; Biocontrol; Biodegradation.

\section{Introdução}

A humanidade sempre procurou novas formas para aprimorar suas condições de vida, aperfeiçoando suas atividades ao longo do tempo e buscando materiais que sejam cada vez mais eficientes e de baixo custo para tais fins (Oliveira, 2013). Dessa forma, o mercado de poliestireno expandido está entre o grupo de materiais que vêm cumprindo essas exigências.

0 poliestireno expandido (EPS, do inglês expanded polystyrene) é um plástico bastante resistente que recebe esse nome por ser resultado da polimerização do estireno em água. Em sua composição há também o pentano, um hidrocarboneto com desintegração facilitada pela reação fotoquímica dos raios solares, que age como expansor desse material. Há muitas aplicações destinadas ao EPS, sendo a principal delas a sua grande capacidade isolante, além de ser um material leve e conferir resistência e impermeabilidade sobre o objeto ao qual protege (Abrapex, 2006).

Porém, a quantidade de resíduos provenientes do EPS é preocupante, sobretudo devido à falta de sua coleta seletiva, uma vez que esta não é considerada economicamente viável. Assim, o EPS tem como destino final os aterros sanitários que resultam num grave problema de poluição ambiental, principal- mente por ser este um plástico derivado do petróleo, uma matéria-prima que não é renovável, que demora cerca de 150 anos para se decompor naturalmente, além de ser difícil de eliminar da natureza (Nukmal et al., 2018).

Neste contexto, a busca pelo descarte e reuso de materiais originados de petróleo promoveram algumas pesquisas que apontam para tratamentos alternativos por meio do uso da nanotecnologia, área que integra os conhecimentos da biologia, química e física para a transformação de materiais eletrônicos, fotônicos, metálicos e poliméricos em novos cosméticos, embalagens e materiais para construção civil (Galembeck et al., 2009).

Durante as pesquisas feitas com larvas de uma espécie de besouro conhecida cientificamente como Tenebrio molitor Linnaeus, 1758 (Coleoptera: Tenebrionidae), uma equipe de cientistas da Universidade de Stanford descobriu que as larvas desse besouro conseguiam se alimentar de pedaços de poliestireno através da presença de bactérias conhecidas como Exiguobacterium sp. que fazem parte da microbiota intestinal dessas larvas (Yang et al., 2015).

Os insetos da Ordem Coleoptera possuem ampla distribuição geográfica, devido à sua grande capacidade adaptativa, sendo encontrados nos mais variados habitats, inclusive àqueles 
modificados pela intervenção humana (Costa Lima, 1952), e pelo intenso comércio de alimentos, principalmente grãos (Mound, 1989).

0 T. molitor é conhecido popularmente como bicho-da-farinha ou simplesmente tenébrio. É um inseto holometábolo e, portanto, sua metamorfose é composta por quatro fases: ovo, larva, pupa e adulto. As larvas atingem cerca de quatro centímetros de comprimento e possuem coloração amarelada com manchas em forma de anéis de cor mais escura pelo corpo. As pupas imaturas são amareladas, mas à medida que se desenvolvem, adquirem tons mais escuros, especialmente nas pernas e na região cefálica. Os adultos apresentam cor negra característica e quando totalmente desenvolvidos medem, em média, $2,5 \mathrm{~cm}$. 0 ciclo de vida se completa em aproximadamente seis meses sob condições favoráveis (Haines, 1991).

Neste contexto, esta pesquisa avaliou a capacidade das larvas de Tenebrio molitor como agentes biodegradadores de poliestireno expandido.

\section{Material e métodos}

Os ensaios foram conduzidos nos laboratórios de Ciências da Saúde da Universidade Paulista, campus Vergueiro, de março de 2016 a setembro de 2017, onde foram mantidas as condições necessárias, tais como luminosidade, abrigo de calor e umidade.

As amostras utilizadas de T. molitor foram adquiridas de criadouro comercial e mantidas em seu substrato original (farelo de trigo integral) para que se reproduzissem livremente e novos indivíduos fossem utilizados nos testes seguintes. Foram fornecidos sempre que necessários elementos úmidos (algodão + água) que serviram como fonte de água e substrato adicional.

Como recipiente para execução e manutenção dos experimentos, foram utilizadas bandejas plásticas brancas $(50 \times 10 \times 30 \mathrm{~cm})$ descobertas, proporcionando circulação de ar às colônias.

Foram formados três grupos de larvas. Cada grupo foi subdividido em três colônias com 30 indivíduos. Em todo o experimento foram utilizados 270 indivíduos.

Cada grupo correspondeu, portanto a um tratamento e este com três repetições, para que os valores fossem relacionáveis.

Em cada tratamento foi oferecido um substrato diferente para o animal viver e se alimentar, sendo respectivamente:

- Grupo 1: Condição semelhante ao ambiente natural: substrato à base de lascas de madeira (serragem) e algodão embebido em água (Figura 1).

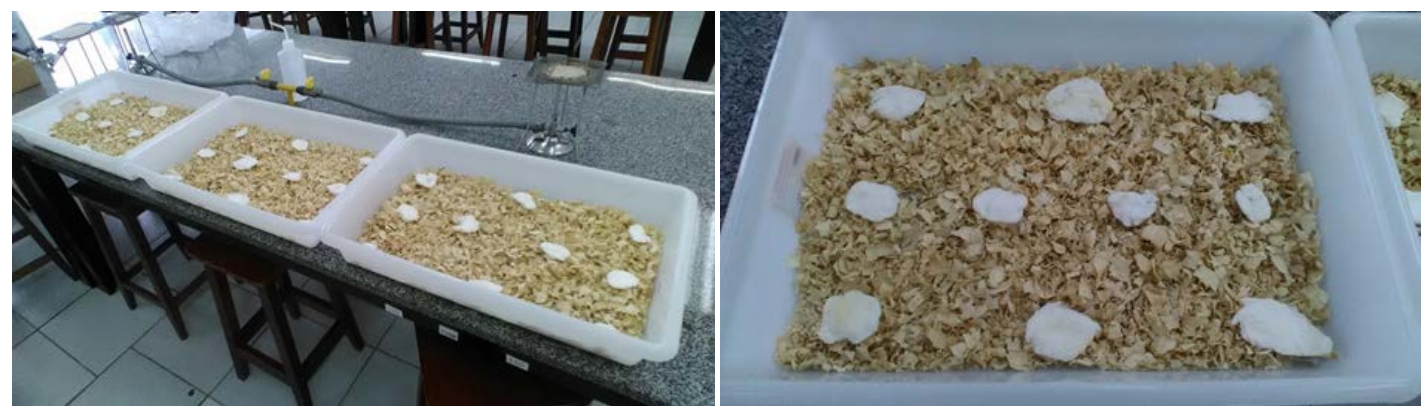

Figura 1. Repetições do Grupo 1 com apenas lascas de madeira. À direita o mesmo material de uma repetição em evidência. 
- Grupo 2: Condição semelhante ao ambiente natural mais EPS: substrato à base de lasca de madeira (serragem), frações de poliestireno expandido e algodão embebido em água (Figura 2).
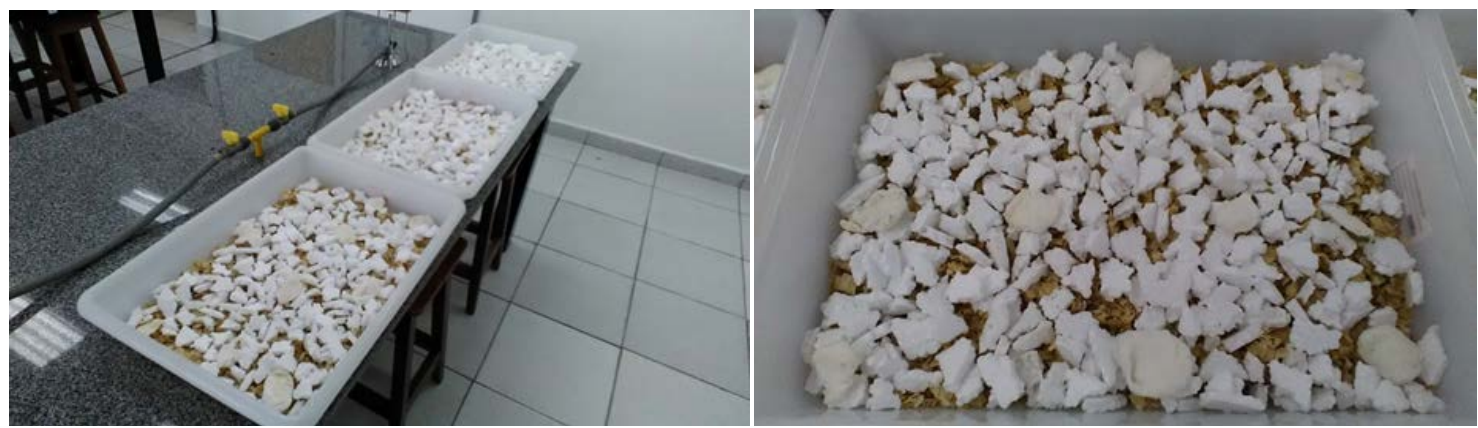

Figura 2. Repetições do Grupo 2, reunindo lascas de madeira e frações de poliestireno expandido. À direita o mesmo material de uma repetição em evidência.

- Grupo 3: Condição não natural e somente EPS: Substrato de pequenas frações de poliestireno expandido e algodão embebido em água (Figura 3).

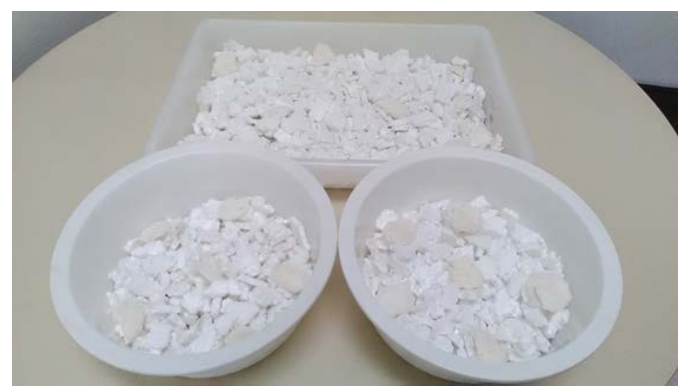

Figura 3. Repetições do grupo 3, com apenas frações de poliestireno expandido.

0 desenvolvimento destes animais foi avaliado no decorrer de seu crescimento.

Foram tomados como critérios o desenvolvimento e crescimento das larvas, sua metamorfose (número de adultos), número de óbitos e tempo médio para ingestão das frações de EPS pela colônia.

A supervisão das colônias foi feita três vezes por dia com pequenas descrições sobre o comportamento das larvas baseado no que foi observado.
A higienização das colônias de larvas era realizada a cada quinze dias, com a retirada de impurezas resultantes da digestão dos insetos e troca do substrato, a fim de proporcionar melhores condições de manejo e observação comportamental.

\section{Resultados}

Conforme descrito na metodologia os animais foram mantidos em diferentes dietas e tais substratos medidos para comparação entre o valor inicial e final.

Na Tabela 1 tem-se os dados do ambiente semelhante às condições naturais com apenas lascas de madeira.

Quando avaliadas somente as lascas de madeira (Tabela 1), o consumo foi diferente entre as três repetições. $\mathrm{Na}$ primeira, o percentual foi de $29,56 \%$, na segunda $8,7 \%$ e na terceira $23,29 \%$, sendo o segundo valor consideravelmente menor que os demais. A média entre os valores percentuais é de $20,52 \%$. Os valores equivalem à média de alimento consumido pelas larvas.

Neste mesmo grupo, na repetição que apresentou o menor consumo de lascas de madeira $(8,7 \%)$ constatou-se o óbito de uma pupa e a mesma foi consumida por quatro adultos do mesmo grupo. 
Tabela 1. Valores antes e após a exposição de Tenebrio molitor a vivência em substrato formado somente por lascas de madeira.

\begin{tabular}{lcccc}
\hline Grupo avaliado & Massa inicial & Massa final & $\begin{array}{c}\text { Massa } \\
\text { consumida }\end{array}$ & $\begin{array}{c}\text { Percentual } \\
\text { consumido }\end{array}$ \\
\hline Repetição 1 & $80 \mathrm{~g}^{*}$ & $56,35 \mathrm{~g}$ & $23,65 \mathrm{~g}$ & $29,56 \%$ \\
Repetição 2 & $100 \mathrm{~g}$ & $91,3 \mathrm{~g}$ & $8,7 \mathrm{~g}$ & $8,7 \%$ \\
Repetição 3 & $94 \mathrm{~g}$ & $72,1 \mathrm{~g}$ & $21,9 \mathrm{~g}$ & $23,29 \%$ \\
\hline
\end{tabular}

*Entende-se g por gramas.

No grupo que foi exposto à combinação de lascas mais EPS (Tabela 2), a primeira repetição consumiu o valor percentual de $12,72 \%$ de lascas de madeira e 4,28\% de EPS, a segunda repetição consumiu $22,57 \%$ de lascas e 2,85\% de EPS e a terceira repetição consumiu $13,76 \%$ de lascas e $4,28 \%$ de EPS. A média de lascas de madeira consumida é de $16,35 \%$ enquanto a média de EPS consumido totalizou $3,80 \%$. Os valores equivalem à média de alimento consumido pelas larvas.

Tabela 2. Valores antes e após a exposição de Tenebrio molitor a vivência em substrato formado por lascas de madeira e poliestireno expandido.

\begin{tabular}{lccc}
\hline Dieta & Repetição 1 & Repetição 2 & Repetição 3 \\
\hline Massa inicial de serragem & $90 \mathrm{~g}^{*}$ & $83 \mathrm{~g}$ & $95 \mathrm{~g}$ \\
Massa final de serragem & $78,55 \mathrm{~g}$ & $64,26 \mathrm{~g}$ & $81,92 \mathrm{~g}$ \\
Massa consumida de serragem & $11,45 \mathrm{~g}$ & $18,74 \mathrm{~g}$ & $13,08 \mathrm{~g}$ \\
Percentual consumido de serragem & $12,72 \%$ & $22,57 \%$ & $13,76 \%$ \\
Massa inicial de EPS** & $7 \mathrm{~g}$ & $7 \mathrm{~g}$ & $7 \mathrm{~g}$ \\
Massa final de EPS & $6,7 \mathrm{~g}$ & $6,8 \mathrm{~g}$ & $6,7 \mathrm{~g}$ \\
Massa consumida de EPS & $0,3 \mathrm{~g}$ & $0,2 \mathrm{~g}$ & $0,3 \mathrm{~g}$ \\
Percentual consumido de EPS & $4,28 \%$ & $2,85 \%$ & $4,28 \%$ \\
\hline
\end{tabular}

*Entende-se g por gramas; **Entende-se EPS por poliestireno expandido.

De acordo com o observado no grupo em que foi oferecido somente frações de EPS (Tabela 3) a primeira colônia consumiu o valor percentual de $24,57 \%$, a segunda colônia consumiu $28,28 \%$ e a terceira colônia consumiu $26,00 \%$ do material disponível. A média de produto consumido totalizou $26,28 \%$.
Os valores equivalem à média de alimento consumido pelas larvas.

Ao término do experimento, verificou-se que a maioria dos indivíduos presentes na Repetição 1 atingiram a fase adulta, com exceção de três larvas que permaneceram neste estágio, vindo a óbito posteriormente.

Tabela 3. Valores antes e após a exposição de T. molitor a vivência em substrato formado apenas por poliestireno expandido.

\begin{tabular}{lcccc}
\hline Grupo avaliado & Massa inicial & Massa final & $\begin{array}{c}\text { Massa } \\
\text { consumida }\end{array}$ & $\begin{array}{c}\text { Percentual } \\
\text { consumido }\end{array}$ \\
\hline Repetição 1 & $7 \mathrm{~g}$ & $5,28 \mathrm{~g}$ & $1,72 \mathrm{~g}$ & $24,57 \%$ \\
Repetição 2 & $7 \mathrm{~g}$ & $5,02 \mathrm{~g}$ & $1,98 \mathrm{~g}$ & $28,28 \%$ \\
Repetição 3 & $7 \mathrm{~g}$ & $5,18 \mathrm{~g}$ & $1,82 \mathrm{~g}$ & $26,00 \%$ \\
\hline
\end{tabular}


Além de utilizarem as frações de EPS como alimento, as larvas construíam túneis que serviam de abrigo, onde passavam grande parte do tempo conforme a Figura 4.

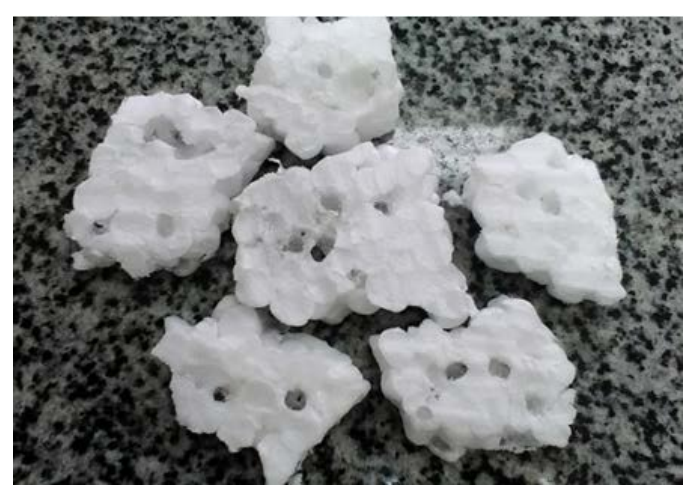

Figura 4. Túneis criados pelas larvas de T. molitor nas frações de poliestireno expandido.

Não se observou variação no crescimento e desenvolvimento dos indivíduos quando expostos a diferentes dietas.

As larvas apresentaram coloração marrom claro e anéis escuros ao longo do corpo que são mais destacados nas regiões cefálica e caudal (Figura 5).
Atingiram em média quatro centímetros de comprimento. Entre sete e onze dias após o início do experimento, as larvas se tornaram pupas.

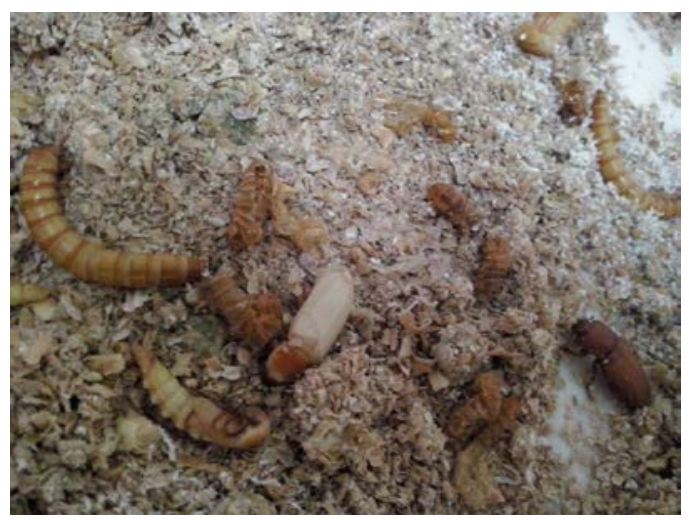

Figura 5. Diferentes estágios de T. molitor.

A pupa imatura teve coloração esbranquiçada e corpo curvado com comprimento médio de dois centímetros (Figura 6). Ao longo de seu desenvolvimento, o corpo adquiriu coloração amarelada e à medida que o tempo passava havia o escurecimento das pernas, cabeça e tórax (Figura 5). Entre treze e dezesseis dias, as pupas tornaram-se adultas.
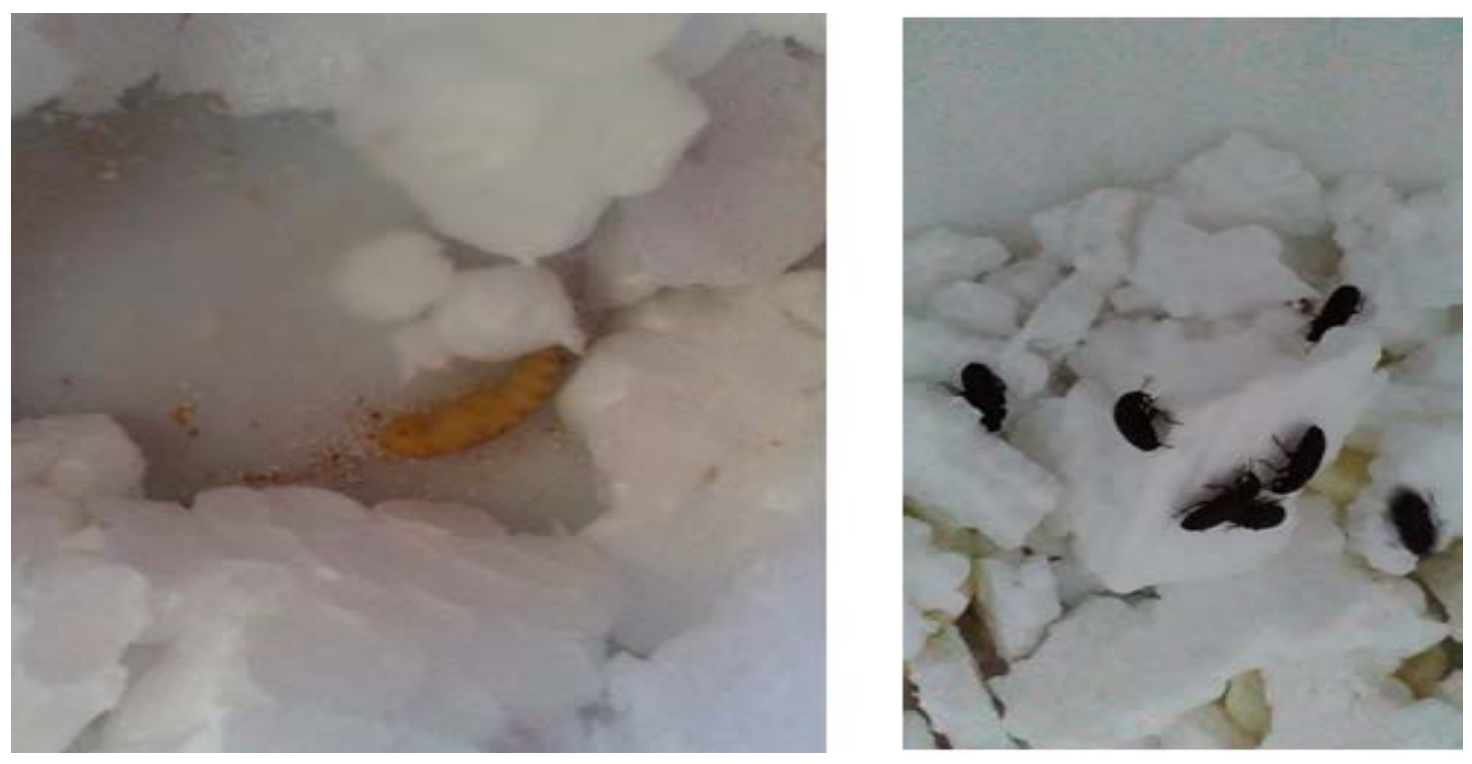

Figura 6. Indivíduos formados no ambiente onde existia somente poliestireno expandido, à esquerda uma pupa e à direita adultos. 
Imediatamente após a metamorfose, os besouros apresentaram dois padrões de coloração. Alguns indivíduos apresentaram o corpo de cor bege clara, porém as pernas, antenas e cabeça de cor marrom. Um a dois dias depois, o corpo inteiro adquiriu coloração marrom (Figura 5) e após mais dois dias, em média, atingia sua coloração negra característica (Figura 6), medindo em média 2,5 cm de comprimento.

Outro resultado interessante ocorreu com uma das colônias com condição semelhante ao natural e adição de EPS: em uma das repetições, o percentual de material consumido foi de apenas 8,7\%, muito abaixo em comparação as demais colônias. Apesar do baixo consumo, o desenvolvimento das larvas não foi afetado, porém não foi possível afirmar se houve prejuízo aos adultos uma vez que não foram pesados.

\section{Discussão}

A utilização de microrganismos em controles de biodegradação tem sido bem explorada nos últimos anos, tanto para matérias orgânicas quanto para inorgânicas. Um exemplo bem sucedido em compostos orgânicos está no reaproveitamento de resíduos gerados pela cultura de bananas que são utilizados como substrato de fermentação para a produção de biogás, processo mediado por bactérias anaeróbias (Souza et al., 2010).

Com relação a matérias inorgânicas, está sendo avaliada a possibilidade de biodegradação dos resíduos gerados pelas etapas de produção, transporte e refinamento de petróleo. Esses resíduos, chamados de borras de óleo, acarretam graves problemas ambientais devido à dificuldade de sua disposição final. Desta forma, a solução pode aparecer com um sistema de biopilhas, que se trata da construção de pilhas de solo poluído com o intuito de estimular atividades microbianas aeróbicas por meio de aeração mais eficiente (Morais, 2005).
De acordo com os resultados do experimento, notou-se maior consumo dos materiais disponibilizados enquanto os indivíduos estavam em sua fase larval. Provavelmente, isso aconteceu devido à necessidade de acúmulo de energia para a realização de ecdises e posterior transição entre as fases de pupa e adulta, respectivamente, pois se tratam de processos em que ocorre grande gasto de energia (Couto-Ferreira et al., 2010).

Com relação aos valores percentuais de alimento consumido, é possível identificar que a média consumida entre os três grupos é equiparável independente do tipo de material utilizado como alimento. Isso pode constatar que a substituição total das lascas de madeira por EPS não altera o desenvolvimento natural dos indivíduos. Porém, os algodões umedecidos presentes nas colônias de condição não semelhante ao natural adquiriam coloração amarela ao longo do tempo, sem motivo aparente, fato que não ocorria nas demais colônias (Figura 7).

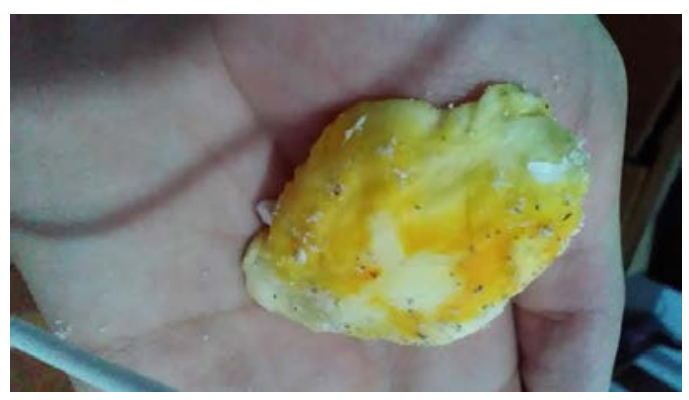

Figura 7. Algodão com aspecto amarelado após permanência no recipiente que abrigava os besouros em substrato apenas de poliestireno expandido.

O estireno, um dos componentes do EPS, em organismo humano, é biotransformado no fígado e pode percorrer quatro vias metabólicas diferentes nas quais interferirá no tipo de substância a ser convertida (Melo, 2009). Porém, é necessário realizar um 
estudo sobre a toxicocinética desse composto no organismo dos besouros para, possivelmente, explicar essa alteração nas tonalidades dos algodões.

Até o presente momento os resultados obtidos foram relevantes e abrem caminhos para a continuidade e esclarecimentos dos dados ainda não compreendidos.

\section{Conclusão}

Com base nas observações relacionadas aos insetos, na qual foi evidenciado que a substituição de dietas aparentemente não interferiu no desenvolvimento dos indivíduos, o T. molitor pode ser utilizado como uma importante ferramenta de destinação para resíduos à base de poliestireno expandido. Isso poderia diminuir a poluição ambiental causada por esse material, pois é sabido que sua decomposição natural leva muitos anos para acontecer.

Essa utilização traria uma nova importância à logística reversa e seria um grande diferencial no mercado de trabalho para as empresas produtoras e/ou consumidoras de embalagens feitas de EPS visto que um material, até então financeiramente inviável para reciclagem, teria um descarte ecologicamente mais correto.

\section{Declaração de conflito de Interesses}

Os autores declaram não haver conflito de interesses.

\section{Referências}

Abrapex - Associação Brasileira do Poliestireno Expandido. 2006. Disponível em: <http://www.abrapex.com.br>. Acesso em: 25 out. 2017.

Costa Lima, A. M. Insetos do Brasil. Coleópteros. Rio de Janeiro: Escola Nacional de Agronomia, 1952. v. 7-10. 1를 e $2^{\underline{a}}$ partes.
Couto-Ferreira, D.; Marques, R.; Guimarães, M. R.; Souza Neto, J. R.; Tinôco, M. S. Estudo comportamental das fases de desenvolvimento do Zophobas morio (Coleoptera, Tenebrionidae) da criação científica do Centro de Ecologia e Conservação Animal ECOA. Revista da Faculdade de Zootecnia, Veterinária e Agronomia, v. 17, n. 2, p. 146158, 2010. Disponível em: <http://revistas eletronicas.pucrs.br/ojs/index.php/fzva/arti cle/view/5377/6117>. Acesso em: 25 out. 2017.

Galembeck, F.; Barbosa, C. A. S.; Sousa, R. A. Aproveitamento sustentável de biomassa e de recursos naturais na inovação química. Química Nova, v. 32, n. 3, p. 571-581, 2009. https://doi.org/10.1590/S0100-40422009 000300003

Haines, C. P. (Ed.). Insects and arachnids of tropical stored products: their biology and identification. 2. ed. Chatham, Kent: Natural Resources Institute, 1991.

Melo, C. K. Reciclagem de materiais poliméricos por incorporação in situ na polimerização em suspensão do estireno. Rio de Janeiro: COPPE/UFRJ, 2009. (Dissertação de mestrado).

Morais, E. B. Biodegradação de resíduos oleosos provenientes de refinaria de petróleo através do sistema de biopilhas. Rio Claro: Instituto de Biociências, Universidade Estadual Paulista, 2005. (Dissertação de mestrado).

Mound, L. Common insect pests of stored food products. 7.ed. Londres: British Museum Natural History, 1989. (Economic series, 15).

Nukmal, N.; Umar, S.; Amanda, S. P. Kanedi, M. Effect of styrofoam waste feeds on the growth, development and fecundity of mealworms (Tenebrio molitor). OnLine Journal of Biological Sciences, v. 18, n. 1, p. 24-28, 2018. https://doi.org/10.3844/ojbsci. 2018.24.28

Oliveira, L.S. Reaproveitamento de resíduos de poliestireno expandido (isopor) em compósitos cimentícios. São João Del Rei: Universidade Federal de São João Del Rei, 2013.

Souza, 0.; Federizzi, M.; Coelho, B.; Wagner, T. M.; Wisbeck, E. Biodegradação de resíduos lignocelulósicos gerados na bananicultura e sua valorização para a produção de biogás. 


\section{Revista Brasileira de Engenharia Agrícola} e Ambiental, v. 14, no. 4, p. 438-443, 2010. https://doi.org/10.1590/S1415-43662010 000400014

Yang, Y.; Yang, J.; Wu, W. M.; Zhao, J.; Song, Y.; Gao, L.; Yang, R.; Jiang, L. Biodegradation and mineralization of polystyrene by plasticeating mealworms: Part 2. Role of gut microorganisms. Environmental Science \& Technology, v. 49 , n. 20 , p. $12087-12093$, 2015. https://doi.org/10.1021/acs.est.5b02 663

CC Informação da Licença: Este é um artigo Open Access distribuído sob os termos da Licença Creative Commons CC Attribution, que permite uso irrestrito, distribuição e reprodução em qualquer meio, desde que a obra original seja devidamente citada. 